\title{
From Financial Markets to Bitcoin Markets: A Fresh Look at the Contagion Effect
}

Roman Matkovskyy (corresponding author)

Department of Finance and Accounting, Rennes School of Business

2 Rue Robert d'Arbrissel, 35000 Rennes

e-mail : roman.matkovskyy@ rennes-sb.com

Tel.: +33 (0)2 99546365

Akanksha Jalan

Department of Finance and Accounting, Rennes School of Business

2 Rue Robert d'Arbrissel, 35000 Rennes

akanksha.jalan@rennes-sb.com

\begin{abstract}
This article studies contagion effects between traditional financial markets, represented by five equity indices and the EUR, USD, GBP, and JPY centralized Bitcoin markets. We apply a regime switching skew-normal model of asset returns that distinguishes between linear and non-linear contagion and also structural breaks in the periods. We find significant contagion effects from financial to Bitcoin markets in terms of both correlation and co-skewness of market returns. Our results also indicate that during crisis periods, risk-averse investors tend to move away from risky Bitcoin markets towards safer financial markets.
\end{abstract}

Key words: Financial markets; Bitcoin; Contagion; Regime Switching Skew-normal Model $(\mathrm{RSSN})$

JEL classification: E31, E44, G12, G15, C34, C11. 


\title{
From Financial Markets to Bitcoin Markets: A Fresh Look at the Contagion Effect
}

\begin{abstract}
This article studies contagion effects between traditional financial markets, represented by five equity indices and the EUR, USD, GBP, and JPY centralized Bitcoin markets. We apply a regime switching skew-normal model of asset returns that distinguishes between linear and non-linear contagion and also structural breaks in the periods. We find significant contagion effects from financial to Bitcoin markets in terms of both correlation and co-skewness of market returns. Our results also indicate that during crisis periods, risk-averse investors tend to move away from risky Bitcoin markets towards safer financial markets.
\end{abstract}

Keywords: financial markets; Bitcoin; contagion; regime switching skew-normal model $(\mathrm{RSSN})$

Acknowledgments: We are grateful to Jonathan Batten, the chief editor, and the anonymous reviewer for the kind and helpful comments to the manuscript. Also, we acknowledge useful comments received from Michael Dowling, Rennes School of Business, France. 


\section{Introduction}

On October 11, 2018, a downturn in equity markets seemingly caused Bitcoin prices to plummet by about $7 \%$. Correspondingly, the Bloomberg Galaxy Crypto Index, Ether, and Litecoin decreased by about $10 \%, 11 \%$, and $13 \%$, respectively. Similarly, the stock market downturn in February 2018 was also publicly believed to have led to a drop in cryptocurrency markets. In light of these occurrences, this paper aims to investigate the spillover effects between equity and cryptocurrency markets.

In this article, we study both the presence of contagion effect and the medium of shock-transmission from equity to cryptocurrency markets. This is important in terms of understanding the impact volatility in traditional equity markets has on other financial markets that could potentially share a part of their investor base. It can also better explain Bitcoin price volatility, something that has puzzled both investors and academics.

Substantial literature that examines the factors driving Bitcoin prices and explaining the volatility therein exists. Matkovskyy (2019) showed that centralized Bitcoin market returns have higher tail dependence. However, volatility results appear contrary to the established leverage theory that postulates that market drops cause volatility. Bariviera et al. (2017) found the standard deviation for Bitcoin prices is 10 times higher than for the euro and the British pound. Baek and Elbeck (2015) noted most Bitcoin volatility is internally driven (by Bitcoin buyers and sellers), rather than externally motivated. Moreover, Dyhrberg (2016) discovered Bitcoin prices are significantly affected by the federal funds rate, endowing them with currency-like characteristics.

Giudici and Abu-Hashish's (2019) research, which examined the spillover effects between different cryptocurrency and between crypto and traditional markets using an extended vector autoregressive model, is the closest to our present study. They found that 
although bitcoin prices from different exchanges are highly interrelated, they are unrelated to traditional market prices. Koutmos (2018) also conducted a similar investigation.

Ciaian et al. (2018) showed that gold prices, exchange rates (USD/EUR and CNY/USD), and the 10-year Treasury constant maturity rate affect Bitcoin prices in both the short and long runs. Corbet, Lucey, Urquhart, et al. (2018) analyzed the interdependence between crypto prices with other financial assets, such as gold, bonds, and stocks, and they found that cryptocurrencies are rather independent of movements in prices of traditional financial assets; this gives them a diversification quality. In a similar spirit, Corbet, Meegan, et al. (2018) documented the relative isolation of cryptocurrencies from other financial and economic assets.

Our contribution both differs from and builds on these prior investigations because we examine the presence of contagion effect and the manner of shock transmissions from conventional financial markets to cryptocurrency markets. To the best of our knowledge, ours is the first paper that directly studies this phenomenon. We employ a new regime switching skew-normal model of asset returns developed by Chan et al. (2018). Contagion is analyzed through channels of co-moments of correlation and co-skewness in two different regimes: at the time of Bitcoin price growth and at a price decrease. These periods coincide with the periods before and after the launch of Bitcoin futures.

Changes in market behavior following the introduction of a new financial instrument, such as futures, is well-documented in literature. Köchling et al. (2018) recognized that with the introduction of Bitcoin futures, Bitcoin markets transitioned from a bullish to bearish phase. For the same reason, we apply structural break tests using two regimes, bullish and bearish times, in Bitcoin markets to better understand investor behavior in the expectation that investor risk preferences may not remain the same during these times. 
Results indicate increased contagion effects from financial to Bitcoin markets, especially from the high-tech industry, both in terms of correlation and co-skewness of market returns, starting December 18, 2017. This might indicate higher integration of Bitcoin markets into traditional financial systems.

This is in contrast to the findings by Bouri et al. (2017), Corbet, et al. (2018), and Giudici and Abu-Hashish (2019), who found no interdependence between Bitcoin and mainstream financial market returns. We attribute our results to increased efficiency in the Bitcoin markets following the launch of Bitcoin futures. First, futures provide the necessary institutional and legal framework for institutions to participate, and this is directly linked to market efficiency (Köchling et al., 2018). Second, futures create opportunities to hedge and speculate in Bitcoin; this is in conjunction with other instruments available in traditional financial markets and results in higher correlation.

Our results also indicate that risk-averse investors tend to shy away from risky Bitcoin markets during crisis periods and lean towards less volatile and more established financial markets, especially NASDAQ and NIKKEI. Our results not only contribute to a better understanding of the Bitcoin markets but also stress the need for a joint analysis of contagion and structural breaks in a multivariate setting.

The remainder of the paper proceeds as follows. Section 2 describes the data and methodology. In section 3, we discuss the empirical results, and in section 4 we offer our conclusions. The online appendix includes supplementary material.

\section{Data and Model Set-up}

The data set covers the daily close prices of Bitcoin denominated in the euro, U.S. dollar, British pound, and Japanese yen in the main centralized Bitcoin markets hosted by GDAX, Bitmap, and BTCBOX. For mainstream financial markets, we selected five equity market 
indices: two USD-denominated and one from each of the three other Bitcoin-denominated currency prices. These markets are NASDAQ100, S\&P500, Euronext100, FTSE100, and Nikkei225. Price data ranges from April 27, 2015 to October 25, 2018 (Figure A1 and A2 in the online appendix). Daily percentage returns were computed as the difference of the natural logarithms of the daily price indices multiplied by 100 .

To analyze contagion effects between financial and Bitcoin markets, a regime switching skew-normal model of asset returns was employed. It is an unrestricted model that allows us to analyze both linear and non-linear contagion between the two markets and also structural breaks in the moment of these markets across selected regimes (Chan et al., 2018). Two regimes are distinguished: an increase in Bitcoin prices in different markets until December 17, 2017, $s_{t}=0$; and a decrease therein after December18, 2017, $s_{t}=1$ (see Figure A1 in the online appendix). This coincides with the launch of the Bitcoin futures on December 17, 2017.

We believe that the regime switching skew-normal model is quite suitable for the purpose at hand because (a) it allows for the correlation and co-skewness contagion parameters to vary in different regimes, and (b) structural breaks in the mean, variance, and skewness are introduced that are potentially useful in cases of asymmetry and heavy tails.

The model is specified as follows (see Chan et al., 2018 for technical details):

$$
\begin{aligned}
& y_{t}=\mu_{s_{t}}+\Omega_{s_{t}} Z_{t}+\varepsilon_{t}, \\
& \varepsilon_{t} \sim N\left(0, \Sigma_{s_{t}}\right), \\
& Z_{t} \sim N\left(C 1_{m}, I_{m}\right) 1\left(Z_{j t}>c, j=1, \ldots, m\right),
\end{aligned}
$$

where $y_{t}=\left(y_{1 t}, \ldots, y_{m t}\right)^{\prime}$ is an m-dimensional random vector, $t=1, \ldots, T, s_{t} \in\{0,1\}$ is a regime at time $t$, where $\operatorname{Pr}\left(s_{t}=1 \mid s_{t-1}=i\right)=p_{i t}$ and $\operatorname{Pr}\left(s_{t}=0 \mid s_{t-1}=i\right)=1-p_{i t}$, that is the probability of state 1 and state 0 , respectively, that vary over time $\left(s_{t}\right.$ is generated by means of a multi-move Gibbs sampling method); mean values $\mu_{s_{t}}$ form an $m \times 1$ vector; $\Omega_{s_{t}}$ is 
an $m \times m$ skewness-co-skewness matrix where the off-diagonal elements are the co-skewness parameters that control asymmetric dependency between the elements of the vector $y_{t} ; Z_{t}=$ $\left(Z_{1 t}, \ldots, Z_{m t}\right)^{\prime}$ is an $m$-dimensional random vector IID; $\varepsilon_{t}$ is an $m \times 1$ vector of innovations that is independent and identically distributed; $\Sigma_{s_{t}}$ is an $m \times m$ error cross-covariance matrix, the constant term $C=-\sqrt{2 / \pi}$ (Sahu et al., 2003); $1_{m}$ is an $\mathrm{m} \times 1$ column of ones; $I_{m}$ is the identity matrix; and $1(\cdot)$ is a scalar indicator function that takes a value of 0 when all $Z_{j t}$ are less then $C$ and 1 otherwise. The parameters are estimated by applying of the MCMC and Bayesian methods.

The likelihood function is defined as

$f(y \mid Z, \Theta, s)=(2 \pi)^{-\frac{m T}{2}} \prod_{t=1}^{T}\left|\Sigma_{s_{t}}\right|^{-\frac{1}{2}} \exp \left\{-\frac{1}{2} \sum_{t=1}^{T}\left[y_{t}-X_{t} \beta_{s_{t}}\right]^{\prime} \Sigma_{s_{t}}^{-1}\left[y_{t}-X_{t} \beta_{s_{t}}\right]\right\}$,

where $\Theta=\left(\beta_{0}, \beta_{1}, \Sigma_{0}, \Sigma_{1}\right), s_{t} \in\{0,1\} . X_{t} \beta_{s_{t}}$ comes from the rewritten Eq. (1) $y_{t}=X_{t} \beta_{s_{t}}+$ $\varepsilon_{t}$, where $X_{t}=\left(I_{m}, I_{m} \otimes Z_{t}^{\prime}\right), \beta_{s_{t}}=\left(\mu_{s_{t}}^{\prime}, \omega_{s_{t}}^{\prime}\right), \omega_{s_{t}}=\operatorname{vec}\left(\Omega_{s_{t}}^{\prime}\right)$. The $\beta_{s_{t}}$ priors are specified as $\beta_{s_{t}} \sim N\left(\underline{\beta}, \underline{V_{\beta}}\right)$

where $\underline{\beta}=\left(\underline{\mu^{\prime}}, \underline{\omega^{\prime}}\right)^{\prime}$ and $V_{\beta}=\left[\begin{array}{cc}\phi_{\mu} I_{m} & 0 \\ 0 & \phi_{\omega} I_{k}\end{array}\right], k=m^{2}$,

while $\Sigma_{s_{t}}$ priors have the inverse-Wishard distribution with degree of freedom $\underline{\tau_{\Sigma}}$ and scale matrix $\underline{S_{\Sigma}}$ :

$\Sigma_{s_{t}} \sim I W\left(\underline{\tau_{\Sigma}}, \underline{S_{\Sigma}}\right)$.

The dynamics of correlation and co-skewness coefficients during the second regime is contagion, while changes in the parameters of moments of the mean, variance, and skewness values are considered to be structural breaks (Chan et al., 2018).

Correlation tests contagion between the selected markets based on an increase in the correlation coefficients as in Forbes and Rigobon (2002). The probability of correlation contagion between the selected markets is therefore: 


$$
\operatorname{Pr}\left(\rho_{i j, s_{t}=1}-\rho_{i j, s_{t}=0}>0 \mid y, M_{u}\right)
$$

The co-skewness contagion test

$$
\omega_{i j, s_{t}=1} \neq \omega_{i j, s_{t}=0}, i \neq j
$$

tests for changes in the asymmetric dependence of returns $i$ and $j$ in regime $s_{t}=0$ compared with regime $s_{t}=1$.

The rationale for structural breaks in the mean for asset market $i$ during $s_{t}=1$ compared to $s_{t}=0$ is based on a reduction in the mean values in periods of financial crisis vis-à-vis non-crisis periods, owing to an expected reduction in returns with the probability:

$$
\operatorname{Pr}\left(\mu_{i j, s_{t}=1}-\mu_{i j, s_{t}=0}<0 \mid y, M_{u}\right)
$$

The test for structural breaks in the variance of the returns of market $i$ follows the idea that the variance of returns will increase during crisis periods (i.e., $\Sigma_{i i, s_{t}=1} \neq \Sigma_{i i, s_{t}=0}$ ). The probability is calculated similarly as in Eq. (7) and Eq. (9).

The structural break tests in skewness of returns $i$ in regime $s_{t}=1$ compared to regime $s_{t}=0$ is based on the Savage-Dickey density ratio. The joint contagion and structural breaks across all the selected markets are also presented.

We compared crucial values from our empirical tests to those in Chan et al. (2018) for better understanding of contagion dynamics (Table A1 in the online appendix). Co-skewness and structural breaks in skewness can be used to analyze patterns in investor behavior because, generally, risk-averse investors prefer positive values of both skewness and coskewness.

\section{Empirical Results}

Table A2 (see the online appendix) provides general statistics under both regimes. Skewness and kurtosis values for Bitcoin and financial markets justify the use of the regime switching skew-normal model (i.e., non-normality in the returns in each market in both periods). 
The contagion test results are provided in Tables A3a to A3e (in the online appendix). Contagion is calculated with respect to equity markets as the source of shocks. The correlations in our contagion tests and mean and variance in structural breaks are probability based. Co-skewness, correlation, and co-skewness in contagion tests and skewness, mean, variance, and skewness in structural breaks are based on the log of the Bayesian factors (see Table A1 in the online appendix for crucial values).

Contagion tests indicate that during periods of crisis in Bitcoin markets, the probability of contagion from the NASDAQ to the selected Bitcoin markets is significantly high (all values of correlation contagion tests are above 0.64 [Table A3a]). This is not unexpected given the scale and scope of the NASDAQ. The correlation channel of contagion also dominates for the NIKKEI225-JPY Bitcoin market (correlation contagion tests $=0.7$ [Table A3e]), the FTSE100-JPY Bitcoin market (correlation contagion tests $=0.68$ [Table A3d]), and Euronext100-JPY Bitcoin market (correlation contagion tests $=0.84$ [Table A3c]).

This might mean these markets became more correlated as Bitcoin prices fell after December 18,2018 . The lowest probability of contagion via correlation is observed for the S\&P500, NIKKEI225, and Euro/USD/GBP markets. The probability of contagion happening jointly via the correlation channels is equal to zero for all the markets.

Although our results contrast with several earlier studies that found virtually no correlation between traditional and cryptocurrency markets, we attribute them to the introduction of Bitcoin futures that seemed to improve efficiency in the Bitcoin markets. For instance, Urquhart (2016) concluded that the Bitcoin market, though currently inefficient, may be in the process of moving towards efficiency. Similarly, Köchling et al. (2018) found the introduction of Bitcoin futures makes the Bitcoin market more informationally efficient.

Hale et al. (2018) noted that the sharp drop in Bitcoin prices after the launch of Bitcoin futures is consistent with typical investor behavior following the introduction of futures in 
asset markets. Before the launch of futures, optimists bid up the price; after it, pessimists cause prices to dip through short selling. Simultaneously, spot volatility increases following the appearance of futures contracts (Corbet, Lucey, Peat, et al., 2018).

Co-skewness contagion tests supported this hypothesis. A direct one-to-one coskewness effect was observed between the NASDAQ and USD Bitcoin markets (coefficient = -2.04 [Table A3a]) and the NIKKEI225 and GBP Bitcoin market (coefficient $=-1.22$ [Table A3e]) and indicate that when Bitcoin prices fall, risk-averse investors jump from Bitmap USD and GDAX GBP Bitcoin markets towards so-called safer havens: the NASDAQ100 and NIKKEI225, respectively. The rest of the co-skewness contagion tests coefficients remained insignificant.

Structural break tests indicated that the selected Bitcoin markets were individually affected by breaks in the means, with higher probability than variances (for which probability equaled 0 for all markets).

The tests revealed structural breaks in skewness for the NASDAQ100/NIKKEI225 and all selected Bitcoin markets, the Euronext100 and the euro and GBP Bitcoin markets, and the FTSE100 and euro Bitcoin market. This reinforces our view that risk-averse investors prefer the NASDAQ100 and NIKKEI225 to USD/GBP/JPY Bitcoin markets after launching Bitcoin futures. Also, these investors prefer European assets to Bitcoins traded in the euro and GDP markets.

Joint contagion and structural break tests used in this paper examined the significance of contagion and structural breaks simultaneously for each market $i$ and jointly for the overall market. Thus, they tested for both crisis and contagion. Joint tests of the mean, variance, and skewness structural breaks for each market showed decisive evidence of structural breaks, further justifying the use of our model. Considering all $m$ markets jointly, we found conclusive empirical evidence for structural breaks in the first to third moments after the 
launch of Bitcoin futures compared to the pre-launch period. These results reinforce our belief that during downturns, contagion and structural breaks should be studied jointly.

\section{Conclusion}

This paper analyzes contagion effects from five equity markets in the United States, Europe, Great Britain, and Japan to USD/EUR/GBP/JPY Bitcoin markets. To the best of our knowledge, ours is the first paper to empirically examine this issue. Given the nature of the data set, a new regime switching skew-normal model of crisis and contagion developed by Chan et al. (2018) was used.

Results indicated that Bitcoin return co-movements were significantly different in Bitcoin futures launch periods compared to the pre-launch period when prices were rising. Bitcoin futures created opportunities for short selling, which resulted in a mass decline in spot demand and, consequently, a drop in Bitcoin prices. This resulted in newer opportunities to hedge and speculate in conjunction with other instruments available in other financial markets; this interdependence increased the post-launch of Bitcoin futures.

Results indicate that risk-averse investors moved from Bitmap USD and GDAX GBP Bitcoin markets towards assets listed on the NASDAQ and NIKKEI225, respectively, in periods of falling Bitcoin prices, as also from Euro/GDP Bitcoin markets to European assets.

Our results emphasize the need for a joint analysis of contagion and structural breaks in a multivariate framework. 


\section{References}

Baek, C., Elbeck, M., 2015. Bitcoins as an investment or speculative vehicle? A first look. Applied Economics Letters. 22,1, 30-34.

Bariviera, A.F., Basgall, M.J., Hasperué, W., Naiouf, M., 2017. Some stylized facts of the Bitcoin market. Physica A: Statistical Mechanics and its Applications. 484, 15 October 2017, 82-90.

Bouri, E., Azzi, G., Dyhrberg, A.H., 2017. On the return-volatility relationship in the Bitcoin market around the price crash of 2013. Economics: The Open-Access, OpenAssessment E-Journal. 11, 2017-2, 1-16.

Chan, J.C., Fry-McKibbin, R.A., Hsiao, C.Y.-L., 2018. A regime swiching skew-normal model of contagion. Studies in Nonlinear Dynamics and Econometrics. 23, 1. https://doi.org/10.1515/snde-2017-0001.

Ciaian, P., Rajcaniova, M., Kancs, D., 2017. Virtual relationships: Short- and long-run evidence from BitCoin and altcoin markets. Journal of International Financial Markets Institutions and Money. 52, January, 173-195.

Corbet, S., Lucey, B., Peat, M., Vigne, S., 2018. Bitcoin futures-What use are they? Economics Letters. 172, 23-27. https://dx.doi.org/10.2139/ssrn.3197634

Corbet, S., Lucey, B., Urquhart, A., Yarovaya, L., 2018. Cryptocurrencies as a financial asset: a systematic analysis. Working paper. http://www.smallake.kr/wpcontent/uploads/2018/05/SSRN-id3143122.pdf

Corbet, S., Meegan, A., Larkin, C., Lucey, B., Yarovaya, L., 2018. Exploring the dynamic relationships between cryptocurrencies and other financial assets. Economics Letters. $165,28-34$.

Dyhrberg, A.H., 2016. Bitcoin, gold and the dollar-A GARCH volatility analysis. Finance Research Letters. 16, 85-92. 
Forbes, K.J., Rigobon, R., 2002. No contagion, only interdependence: Measuring Stock market comovements. The Journal of Finance. 57, 5, 2223-2261.

Giudici, P., Abu-Hashish, I., 2019. What determines bitcoin exchange prices? A network VAR approach. Finance Research Letters. 28, March 2019, 309-318.

Hale, G., Krishnamurthy, A., Kudlyak, M., Shultz, P., May 7, 2018. How futures trading changed Bitcoin prices. FRBSF Economic Letter. 2018-12. https://www.frbsf.org/economic-research/publications/economicletter/2018/may/how-futures-trading-changed-bitcoin-prices/

Jeffreys, H., 1961. Theory of Probability. Clarendon Press, Oxford, Third Edition.

Köchling, G., Muller, J., Posch, P.N., 2018. Does the introduction of futures improve the efficiency of Bitcoin? Finance Research Letters. https://dx.doi.org/10.2139/ssrn.3129624

Koutmos, D. 2018. Return and volatility spillovers among cryptocurrencies. Economics Letters. 173, C, 122-127.

Matkovskyy, R. 2019. Centralized and decentralized bitcoin markets: Euro vs USD vs GBP. The Quarterly Review of Economics and Finance. 71, February, 270-279.

Sahu, S.K., Dey, D.K., Branco, M.D., 2003. A new class of multivariate skew distributions with applications to Bayesian regression models. The Canadian Journal of Statistics. $31,2,129-150$.

Urquhart, A., 2016. The inefficiency of Bitcoin. Economics Letters. 148, C, 80-82. 